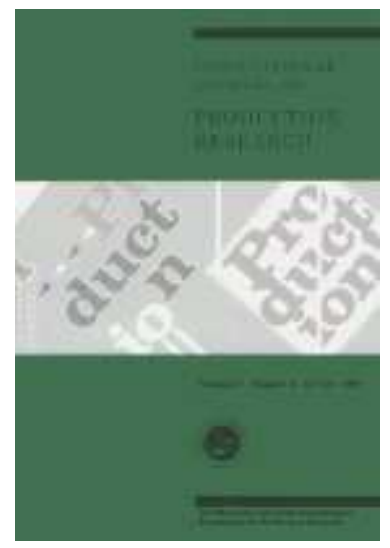

\title{
Optimizing and simulating the assembly line balancing problem in a motorcycle manufacturing company: a case study
}

\begin{tabular}{|c|c|}
\hline Journal: & International Journal of Production Research \\
\hline Manuscript ID: & TPRS-2009-IJPR-0059.R1 \\
\hline Manuscript Type: & Original Manuscript \\
\hline $\begin{array}{r}\text { Date Submitted by the } \\
\text { Author: }\end{array}$ & 10-Mar-2009 \\
\hline Complete List of Authors: & $\begin{array}{l}\text { Cortes, Pablo; University of Seville, Industrial Engineering } \\
\text { Onieva, Luis; University of Seville, Industrial Engineering } \\
\text { Guadix, Jose; University of Seville, Industrial Engineering }\end{array}$ \\
\hline Keywords: & $\begin{array}{l}\text { ASSEMBLY LINE BALANCING, LEAD-TIME REDUCTION, SIMULATION } \\
\text { APPLICATIONS }\end{array}$ \\
\hline Keywords (user): & motorcycle \\
\hline
\end{tabular}

\section{今 ScholarONE" \\ Manuscript Central}




\title{
Optimizing and simulating the assembly line balancing problem in a motorcycle manufacturing company: a case study
}

\author{
Pablo Cortés* , Luis Onieva, José Guadix \\ Ingeniería Organización, University of Seville, Spain
}

Escuela Superior Ingenieros, Camino de los Descubrimientos s/n. E-41092 / Sevilla SPAIN

\begin{abstract}
In this paper, we present a real life assembly line balancing problem for a motorcycle manufacturing company. Results from the initial situation in the company are compared to those provided by a heuristic method and by a novel neighbourhood search method. An ARENA simulation model is developed to test the different proposals. The model was validated by comparing the simulation results from the initial company scenario with the real operation results. Consequently, the extension to the developed proposals allows us to select an adequate assembly line for the company, resulting in a greater productivity level and a more balanced line with respect to the operation times in the stations and the activity of the workers. The company has subsequently implemented our proposed schedule, obtaining remarkable improvements in its productivity.

Keywords: motorcycle, assembly line, lead time, simulation
\end{abstract}

\section{Introduction}

Automobile manufacturing is the industry sector that makes greatest use of assembly lines. The problem of design and balancing of assembly lines is difficult to be solved due to its combinatorial nature (Wee and Magazine, 1982) and also due to the large amount of constraints and tasks to be carried out in real life problems.

An assembly line is a manufacturing process in which parts are added to a product in a sequential manner using optimally planned logistics to create a finished product much faster than with handcrafting-type methods. Essentially, the main aspects of assembly lines are the number of stations and the production rate. In the case we are dealing with in our paper, every worker is supposed to have the same amount of time for carrying out the operations that are associated to his/her post, C. Consequently, $1 / \mathrm{C}$ is the production rate better performance for the whole of experiments, which should be sufficient to meet the required demand.

\footnotetext{
* Corresponding author: pca@esi.us.es / Tel. +34 954486134
} 
Operations (or tasks) are assigned to the stations where the workers assemble the parts and subcomponents, depending on the precedence constraints between operations, the fixed stations constraints where an operation may have to be carried out, and the incompatible tasks constraints for operations that cannot be carried out in the same station. Assembly lines can also include many other specific constraints such as linked tasks, cumulated restrictions, excluded stations, station type, and minimal/maximum distance, amongst others. An interesting web page addressing most of the well-known problems in assembly lines can be accessed in the site www.assembly-line-balancing.de.

This paper discusses manufacturing assembly line performance improvement of a company that produces motorcycles named $\mathrm{MH}$, whose main factory is located in Spain. It is the most southern automobile industry company in Europe and the majority of its production (more than $75 \%$ ) is destined for export. Currently, the most outstanding product of the company is the FURIA XP6 model (Figure 1), which is the model we analyse in this paper.

\section{FIGURE 1}

This paper focuses on the assignment of operations to the assembly line, comparing the previous scheduling in the company with diverse proposals. We address a method based on the traditional rank positional weight heuristic, which is adapted to the specific conditions of motorcycle assembly when two people must be always working on the vehicle at each station, and a neighbourhood search heuristic, which provided the better quality results. This neighbourhood search heuristic 
algorithm has since been successfully implemented in the factory. Simulations are shown for all the cases, thus allowing the comparison between proposals.

In a general scope the assembly line problem has been widely studied in scientific literature, being surveyed by several authors (Rekiek et al., 2002; Becker and Scholl, 2006; Scholl and Becker, 2006; or Boysen et al., 2007 as recent examples). Focusing on real case studies, an interesting paper (Lapierre and Ruiz, 2004) addresses a case study in the Canadian industry of appliances. The paper considers a two-sided conveyor with different speeds and grouping characteristics that make it different from other traditional cases. The problem was solved by implementing a priority-based heuristic developed in MsAccess. However, there are not many research papers dealing with the specific problem of motorcycle production. Pastor and Corominas (2000) studied the assembly line balancing problem with incompatibilities and bounded workstation loads in a motorcycle factory. They presented the case of a single-sided line with a given number of stations and different types of assignment restrictions: some tasks are required to be assigned to the same station and, thus, they may be combined to a single task; some tasks can only be performed at the left hand or the right hand side of a large, irremovable workpiece; and some tasks need to be executed at the top or at the bottom of the workpiece. The specific characteristics of the current assembly line imply a number of specific constraints that must be taken into account when considering their paper, differing from the case study we are addressing here. More recently, some of the same authors (Corominas et al., 2008) have presented the process of rebalancing in a motorcycle assembly line with the aim of reducing the number of temporary workers. This problem considers workers with different skills that must be correctly assigned to 
stations in order to achieve the maximum productivity. Their paper differs in this respect from ours where all the workers are stable in the company staff. Additionally, we can assume that resources are homogeneous, and hence the task duration is not depending on its workstation allocation. Some of the same authors have continued researching on motorcycle assembly lines cases; it is the case of the alternative subgraphs assembly line balancing problem recently addressed in Capacho and Pastor (2008), or the papers by Andrés et al. (2008), and Pastor and Ferrer (2009). However, our paper relates more to Akagi et al. (1983) and Lutz et al. (1994) where the performance of workers on a specific task is the same. The difference from our work relies on the specific characteristic of a motorcycle assembly line where exactly two persons have to work at the same time at each station.

The rest of the paper follows with the second section, which includes the description of the assembly line and the operations that are needed to produce a FURIA XP6 motorcycle model. The third section details the previous scheduling in the assembly line in the company, as well as the proposals that were considered. Expected results from a theoretical point of view are also shown. The fourth section is dedicated to the simulation model and the results that the simulation model provided using ARENA software. Finally, the main aspects are reviewed in the conclusion.

\section{Description of the assembly line for FURIA XP6 model}

The main parts of a motorcycle are: the chassis, which constitutes the backbone of the motorcycle and is where the rest of the components are assembled; the clutch-release yoke, which joins the handlebars to the front wheel and acts as front suspension; a tipping device to join the rear wheel and the rear muffler; the petrol deposit; the engine, which is joined to the dumper and to the rear wheel by a chain or belt with the 
objective of propelling the whole vehicle; and the front and rear brakes to stop the motorcycle.

The FURIA XP6 motorcycle assembly line is fed from manufacturing cells located near the corresponding station. Figure 2 depicts the layout of the manufacturing zone of the factory, where the assembly lines are located. Because Due to this model representing the largest part of the company's sales, there is one specific line dedicated to the model: assembly line 1 . The other line is used for the company's remaining models. The assembly lines are operated in a discontinuous manner. The tasks are done with the chain stationary, and once the workers have finished their tasks the chain advances.

\section{FIGURE 2}

Figure 2 depicts one individual characteristic of motorcycle assembly lines. The morphology of motorcycles allows two operators to work on a vehicle at the same time but on separate tasks, or while collaborating on a more complex task.

57 operations are carried out for the FURIA XP6 model and are described in Table 1, where the average time and standard deviation have been measured for each task. In our case, we need to consider precedence constraints between operations, some fixed stations constraints where an operation has to be carried out (e.g. the chassis assembly), and incompatible tasks constraints for operations that cannot be carried out at the same station. The table also indicates when an operation must be carried out by both operators (B), and when by the right (R) or left (L) one. The table states the operations as they were carried out in the initial scenario.

\section{TABLE 1}

We have to note related to Table 1 , that we carried out a checking analysis trying to identify which tasks were forced to be undertaken by "both" operators with 
the objective to relax this restriction in an hypothetical re-assembly. We proposed to assign operation 7 (firstly assigned to B) to the left operator due to assembly reasons, and tasks $14,22,48$, and 51 that were initially conditioned to both operators to one of them (indistinctively to the left or right operator). These proposals were checked during the Christmas planned maintenance stop and then approved by the General Manager after checking its feasibility.

Once we have calculated the average times of each operation, $t_{i}$, for $N$ operations, we can calculate the total assembly time, $T$, and given a number of stations, $K$, and a lead time, $C$, we can calculate the inactivity time $I=K \cdot C-T$. Thus, the objective of our problem is to minimize the lead time, $C$.

Figure 3 depicts workers on the assembly line carrying out operations detailed in Table 1.

\section{FIGURE 3}

\section{Scheduling of operations on the assembly line: previous situation and proposals}

Let $\left\{J_{1}, J_{2}, \ldots . . J_{N}\right\}$ the set operations to be carried out on the assembly line. The execution time for the operations is known from Table 1, and is given by $t_{i}, i=1, \ldots \ldots . . N$. The precedence constraints among operations are also known. As previously stated, the unique feature of motorcycle assembly lines is that two operators can carry out operations at the same time, or cooperate to carry out a more complex operation. The goal is to assign operations to stations with the objective of minimizing the lead time.

\subsection{Previous situation}

The initial scheduling of the assembly line is described in Table 2.

\section{TABLE 2}


As can be seen, the initial situation depicts an assembly line that is poorly balanced, with two stations ( 1 and 2) much busier than the others ( 3 and 4 ). The expected lead time is 0:12:49.

Additionally, 
Table 2 shows the operations that have to be carried out by two operators simultaneously, due to the special requirements of the task. The other operations can be interchangeable between the right and left operator.

The table also includes waiting times. Idle times can result due to: (i) worker A is waiting for worker B to make a joint operation or (ii) worker A is waiting for worker B because worker A's operation relies on worker B's operation being completed.

\subsection{Modified Rank Positional Weight Heuristic (MRPWH)}

First, we tried a new scheduling given by a heuristic based on the Rank Positional Weight Heuristic (RPWH) adapted to the unique situation of two operators working on the same vehicle on an assembly line. RPWH is an old reputed heuristic method (Helgeson and Birnie, 1961). We detail our modification of RPWH below in the following rules:

- A weight is assigned to each operation $J_{i}$ according to $p_{i}=t_{i}+\sum_{i \in D} t_{i}$. The weight is calculated as the operation $J_{i}$ time plus the time of all the operations that must follow operation $J_{i}$, that are stated as set $D$ in the formula.

- Operations are ordered in decreasing order of weight, safeguarding the precedence relationship. This configures an assignment list.

- An approximate lead time is estimated as the sum of the operations' average time, divided by the number of stations and then multiplied by two due to the number of operators (in our case: 8).

- Operations are assigned to operators following the order of the assignment list and according to the position requirements (left, right or both) up to satisfy the lead time (the nearest possible value to the lead time). First, in case of position requirement, the constraint is satisfied by assigning the operation to the specified operator. Second the rest of operations are assigned to left or right operator attending to his/her work load in the station and with the objective of minimizing the idle time.

- The station's total time is calculated for the four stations.

- The lead time is calculated as the maximum of the four stations.

Table 3 shows the scheduling proposal according to the MRPWH technique.

\section{TABLE 3}


As can be seen, the lead time is reduced from 0:12:49 to 0:07:29, which is approximately $41 \%$ of the time saved, after applying MRPWH.

\subsection{Multi-Started Neighbourhood Search Heuristic (MSNSH)}

We developed a novel multi-started neighbourhood search heuristic, with the aim of providing a more balanced assembly line.

Feasible solutions are encoded as Figure 4 depicts. The figure shows the encoding for the scheduling, corresponding to the factory's initial scenario. Each feasible schedule corresponds to a feasible solution, where three arrays are used for each possible worker distribution (right or left worker and both workers) at each station. The number of registers for the arrays of the stations must be sufficient, with the remaining non-used registers equal to blanks.

\section{FIGURE 4}

Given a feasible solution, $x_{i}$, the quality of the feasible solution, $f\left(V_{i}\left(x_{i}\right)\right)$, is estimated as the inverse of the lead time.

For a feasible solution, $x_{i}$, we consider a weak neighbourhood and a heavy neighbourhood. The search is firstly carried out into the weak neighbourhood and then in the heavy one.

The weak neighbourhood consists of the interchanging of operations within the bottleneck station, $E$, and is named $V^{E}\left(x_{i}\right)$. This weak search is carried out during $N_{w}$ iterations.

The heavy neighbourhood consists of the interchanging of operations between any pair of stations and is named $V\left(x_{i}\right)$. This search is carried out during $N_{H}$ iterations.

Every neighbour of any neighbourhood is depicted as $V_{i}\left(x_{i}\right)$. In both cases the search for a better solution inside a neighbourhood is attempted during $N_{\text {loop }}$ iterations. 
Feasibility controls are required due to the precedence or position constraints. Only feasible solutions are considered, with the others being disregarded. The pseudocode of the algorithm is presented in Table 4 .

\section{TABLE 4}

The heuristic was initiated starting from the $\mathrm{MH}$ initial solution, from the solution provided by the MRPWH and from three other slight modifications from these two scheduling proposals.

We implemented 700 iterations for the weak neighbourhood search $\left(N_{w}\right), 300$ iterations for the heavy neighbourhood search $\left(N_{H}\right)$ and 40 iterations were carried out inside the searching loop $\left(N_{\text {loop }}\right)$, obtaining a computational time equal to approximately 950 seconds per each search process.

Table 5 shows the scheduling proposal according to the MSNSH heuristic method. Changes are mainly incorporated in stations 3 and 4 with respect to the proposal of the MRPWH method. These stations are critical and correspond to the bottleneck station identification during the computation of the neighbourhood search algorithm.

\section{TABLE 5}

Results show an improvement in the lead time equivalent to a reduction of 34 seconds (the new average lead time is assessed at 0:06:55).

\section{Simulation and comparison of proposals using ARENA}

We analysed the productivity and other performance indexes of the different proposals by developing a simulation model using ARENA simulation software, Kelton et al (2007). Simulation software is especially useful for testing the efficiency of a new schedule prior to its implementation in real life, and allows the statistical data to be considered. Additionally we could contrast the level of accuracy of our 
simulation model by comparing it with the real situation that was implemented in the factory at that time.

We supposed the following hypothesis: the workers have all the material and required tools at their disposal, and the material is supplied to the line without interruption.

Times of operations were defined as having a normal distribution following Table 1. A whole labour turn of 8 hours was simulated. This time horizon allows for the variability of the results. The operations described in Table 1, together with the waiting queues that have to be considered due to possible delays (it is usual that a worker has to wait for the other worker in order to carry out a subsequent operation), are modelled using the constructive modules of ARENA.

The simulations of the MH initial scenario were particularly useful because this scenario allowed the validation of the simulation model (the results from the simulation were in accordance with the actual operation in the factory plant).

\subsection{Simulation model}

A simulation model was constructed for each specific solution. They all included some common parts and other different parts, depending on the specific scheduling of each solution. Figure 5 details the operation of the four stations of the assembly line for each case.

\section{FIGURE 5}

The first module defines the station, and the second module assigns the motorcycle in process to the station. The motorcycle then enters the corresponding module Station that is defined in the following figures 6 and 7, and which includes the operations that are carried out inside each station. Once the operations have been carried out, an "assign" module follows, stating that the station operations on the 
motorcycle have been completed in that station. Now the entity enters a "hold" module where it waits for the remaining operations to be completed. The "route" module transports the entity from one station to the next.

The main building blocks are included in the Station module where the operations are implemented. Figure 6 and Figure 7 represent the simulation model for the schedule provided by the MSNSH heuristic.

\section{FIGURE 6}

\section{FIGURE 7}

Figure 7 addresses the operations in station 4 , the most complex of the stations, and where the majority of operations are realized. The bottleneck of the production rate is described, as the following results show. The operations have been represented by "process" modules, where the resources are specified (which worker carried out the operations), and the operation time has a statistical normal variable. Taking into account that workers can carry out operations at the same time, the entity is duplicated by a "separate" module named 'Duplicated'. Finally, both entities are rejoined by a "batch" module named 'Junction'. The figures include, together with the operation modules, some "hold" and "assign" modules that are included to represent the precedence relations and the waiting times between workers.

The processes for the MRPWH heuristic and the MH initial scenario are similar, apart from modifying the location of the operations that are interchanged in the scheduling, as can be seen in Tables 2, 3 and 4 .

The simulation animation module is shown in Figure 8.

\section{FIGURE 8}




\subsection{Comparison of results}

This subsection shows the results for three schedules, focusing on the operation time for each station, the waiting times between workers and between stations, and the activity of the workers. The analysis of these three cases allows the efficiency and suitability of each schedule to be analysed.

Figure 9 depicts the operation time for each proposal analysed in each station. MRPWH and MSNSH heuristics clearly outperform the initial proposal, providing a more balanced assembly line. In the initial situation the bottleneck was located in station 2, whereas MRPWH and MSNSH proposals locate the bottleneck in station 4, reducing the lead time drastically. However, some replications located the bottleneck in station 3 due to the variability (normal distribution) of the tasks' operation times. By analysing Figure 9, we can also appreciate that MSNSH slightly improves the operation time provided by MRPWH.

\section{FIGURE 9}

It has to be taken into account that the location of the bottleneck is not particularly relevant, due to the individual nature of the assembly line conveyor, which moves in a discontinuous manner. The conveyor is consequently not activated until all the operations are completed, resulting in it being impossible to carry out work in advance, because the work in process (which is fastened to the line) cannot be displaced.

The idle times vary depending on the nature of the wait. Figure 10 shows the different waiting times of workers in the same station (top side), which occur when one worker has to wait for another worker to complete a task, as well as the waiting times that occur between stations (down side), appearing due to a non-exact balance.

\section{FIGURE 10}


Figure 10 shows how MRPWH and MSNSH proposals reduce the idle time with respect to the initial scenario, focusing on both types of waits. The reduction is much greater in the second case (down side of the figure). These reductions result in a lower lead time, as Figure 9 depicted.

Figure 11 represents the activity of the workers in the assembly line. The images show a very balanced activity for MRPWH and MSNSH proposals, (being better in the MSNSH case). The initial scenario showed a very unbalanced situation with a great amount of activity for the first two stations and a very low level of activity in the final two stations.

\section{FIGURE 11}

Finally, the production level of motorcycles can be appreciated in Table 6 and Figure 12. Both MRPWH and MSNSH schedules produce a much larger number of motorcycles per day, with the MSNSH proposal producing the better values, with a higher average value, and a lower standard deviation, which is another important factor.

\section{TABLE 6}

\section{FIGURE 12}

\section{Conclusion}

This paper deals with a motorcycle factory real case study that corresponds to a discontinuous assembly line balancing problem. We implemented a traditional heuristic method that was adapted to the specific characteristics of a motorcycle assembly line (MRPWH). The heuristic proposal was compared with the output of a neighbourhood search method (MSNSH). 
We constructed a simulation model to test the different proposals. The simulations of the initial scenario permitted the validation of the simulation model. The results from the simulation were in fact in accordance with the factory plant's current operation.

Both MRPWH and MSNSH provided much better solutions than the model implemented in the initial scenario. Also, the MSNSH proposal was slightly better than the MRPWH proposal, creating a greater productivity level and a more balanced line, which affected the operation times in the stations as well as the activity of the workers. Furthermore, the MSNSH schedule was so balanced than the bottleneck varied from station 3 to station 4 , depending on the simulation replication, although it was mainly located in station 4 . The measurement of the tasks' time by a statistical distribution allows a real representation of the current situation in the factory.

$\mathrm{MH}$ is at present implementing the MSNSH schedule in its factory, obtaining a productivity level of between 55 and 59 motorcycles (most of the days it is 56). However, the efficiency of the workers is continuously improving, so the data in Table 1 is being revised. Additionally, new components are included in, or removed from, the motorcycle models each year. Due to all of these factors, the balancing of the assembly line must be continuously monitored and rebalanced in order to achieve better results and attain a state of continuous improvement.

\section{References}

Akagi, F., Osaki, H. and Kikuchi, S., 1983, A method for assembly line balancing with more than one worker in each station. International Journal of Production Research 21 (5): 755-770.

Andrés, C., Miralles, C. and Pastor, R., 2008, Balancing and scheduling tasks in assembly lines with sequence-dependent setup times. European Journal of Operational Research, 187 (3): 1212-1223.

Becker, C. and Scholl, A., 2006, A survey on problems and methods in generalized assembly line balancing. European Journal of Operational Research 168: 694-715. 
Boysen, N., Fliedner, M. and Scholl, A., 2007, A classification of assembly line balancing problems. European Journal of Operational Research, 183: 674693.

Capacho, L. and Pastor, R., 2008, ASALBP: the alternative subgraphs assembly line balancing problem. International Journal of Production Research 46 (13): 3503-3516.

Corominas, A., Pastor, R. and Plans, J., 2008, Balancing assembly line with skilled and unskilled workers. OMEGA, The International Journal of Management Science, 36(6): 1126-1132.

Helgeson, W.B. and Birnie, D.P., 1961, Assembly Line Balancing Using Rank Positional Weight Technique. Journal of Industrial Engineering 12(6): 302310.

Kelton, W.D., Sadowski, R.P. and Sturrock, D.T., 2007, Simulation with ARENA. McGraw-Hill International Edition.

Lapierre, S. and Ruiz, A.B. (2004). Balancing assembly lines: an industrial case study. Journal of the Operational Research Society 55: 589-597.

Lutz, C.M., Davis, K.R. and Turner, C.F., 1994, Development of operator assignment schedules: a DSS approach. Omega 22: 57-67.

Pastor, R. and Corominas, A., 2000, Assembly line balancing with incompatibilities and bounded workstation loads. Ricerca Operativa 30: 23-45.

Pastor, R. and Ferrer, L., 2009, An improved mathematical program to solve the simple assembly line balancing problem. International Journal of Production Research. doi: 10.1080/00207540701713832.

Rekiek, B., Dolgui, A., Delchambre, A. and Bratcu, A., 2002, State of art of optimization methods for assembly line design. Annual Reviews in Control 26: 163-174.

Scholl, A. and Becker, C., 2006, State-of-the-art exact and heuristic solution procedures for simple assembly line balancing. European Journal of Operational Research 168: 666-693.

Scholl, A., Boysen, N., Fliedner, M., and Klein, R. Homepage for assembly line optimization research. Site: http://www.assembly-line-balancing.de/. Accessed in 2009, March.

Wee, T.S. and Magazine, M.J., 1982, Assembly line balancing as generalized bin packing. Operations Research Letters 1: 56-8. 


\section{TABLES}

Table 1. Operations in the $\mathrm{MH}$ assembly line as they were carried out in the initial scenario

\begin{tabular}{|c|c|} 
Precedence Position Average time Standard deviation & Operation \\
\hline
\end{tabular}

2 Clutch-release yoke

3 Tipping device

4 Rear fastening

5 Snubber

6 Handlebars

7 Engine

8 Rear wheel shaft

9 Rear wheel

10 Rear brake installation

11 Front wheel shaft

12 Front wheel

13 Mileometer

14 Front brake

15 Rear chassis

16 Rear brake connection

17 Electrical installation

18 Crankcase oil

19 Engine connection

20 Left radiator grille

1

$\begin{array}{ll}1 & \text { B } \\ 2 & \text { B }\end{array}$

$0: 00: 10 \quad 0: 00: 04$

31 Pinion cover

0:00:11 32 Left wire guidance

$0: 00: 22$
$0: 00: 35$

$0: 00: 11$

$0: 00: 34$

0:00:03

0:00:09

$0: 00: 37$
$0: 01: 16$

33 Right wire guidance

34 Front mudguard

35 Petrol tank flange

0:00:22

B $\quad 0: 01: 22$

0:00:09

0:00:09 0:00:04

0:01:00

0:00:06

0:00:16

0:00:02

0:00:06

0:01:07

0:00:04

0:00:12

0:00:15

0:00:23

0:00:34

0:00:09

0:00:30

$0: 00: 26$

0:00:18

0:00:08

0:00:29

22 Electrical installation (handlebars) 7,13,14,17

L 0:01:04

0:01:04

6 Petrol tank

37 Radiator antifreeze

38 Relief valve sleeve (right)

39 Oil fill

40 Brake pedal

41 Right rear cover

42 Right rear indicator

43 Right front cover

44 Exhaust pipe

45 Muffler

46 Rear mudguard

47 Left rear cover

48 Connection mudguard-license plate

49 Left rear indicator

50 Left front cover

51 Head lamp holder

0:00:11 52 Seat

24 Radiator 17,19,22

25 Right radiator

0:00:21

$0: 00: 10$

27 License plate holder framework

24

$0: 00: 24$

53 Carburettor connection

0:00:16

0:00:06

28 Chain

$\begin{array}{lll}29 & \mathrm{R} & 0: 00: 43 \\ 9 & & 00: 18\end{array}$

54 Oil filter sleeve

55 Clutch wire connection

0:00:35 $\quad 56$ Petrol plug vent

0:00:23

57 Clutch wire

Precedence Position Average time Standarc

29 License plate holder

15,17

$0: 01: 15$

0:00:50

0:00:15

\begin{tabular}{|c|c|c|}
\hline 28 & $\mathrm{~L}$ & $0: 00: 27$ \\
\hline 22 & & $0: 00: 35$ \\
\hline 22 & & 0:00:28 \\
\hline $22,32,33$ & & $0: 00: 40$ \\
\hline $17,19,22,30,37,38,39,45$ & & 0:00:38 \\
\hline 35 & & $0: 00: 14$ \\
\hline 24 & $\mathrm{R}$ & 0:00:41 \\
\hline 19,44 & & 0:00:20 \\
\hline 23 & $\mathrm{R}$ & 0:00:20 \\
\hline 1 & $\mathrm{R}$ & $0: 00: 37$ \\
\hline 46 & $\mathrm{R}$ & 0:01:00 \\
\hline 29 & & 0:00:59 \\
\hline 36 & $\mathrm{R}$ & 0:00:56 \\
\hline $19,20,30$ & $\mathrm{~L}$ & $0: 00: 45$ \\
\hline 44 & $\mathrm{~L}$ & 0:00:41 \\
\hline 29 & & $0: 00: 31$ \\
\hline $30,36,38,45,46$ & $\mathrm{~L}$ & 0:01:13 \\
\hline 46,29 & B & $0: 00: 50$ \\
\hline 29 & & $0: 00: 25$ \\
\hline 45,36 & $\mathrm{~L}$ & $0: 00: 47$ \\
\hline $22,19,32,33$ & B & 0:02:05 \\
\hline $41,43,46,47,50$ & & 0:00:57 \\
\hline 7,6 & & 0:03:12 \\
\hline 15,7 & & $0: 00: 30$ \\
\hline 57 & & $0: 00: 23$ \\
\hline 36 & & 0:00:11 \\
\hline 6,7 & & 0:00:52 \\
\hline
\end{tabular}


Table 2. Initial scheduling in the assembly line

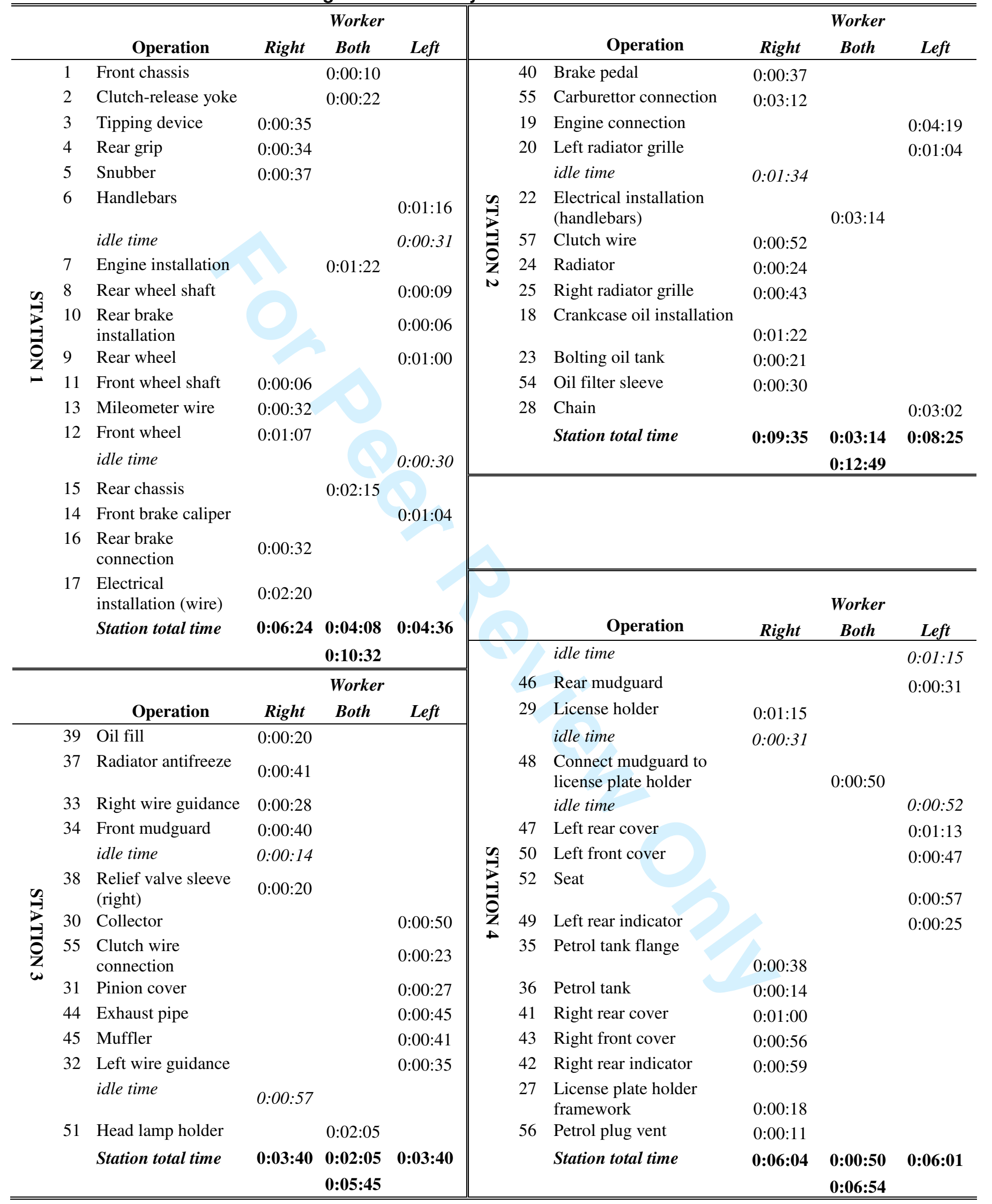


Table 3. MRPWH scheduling proposal

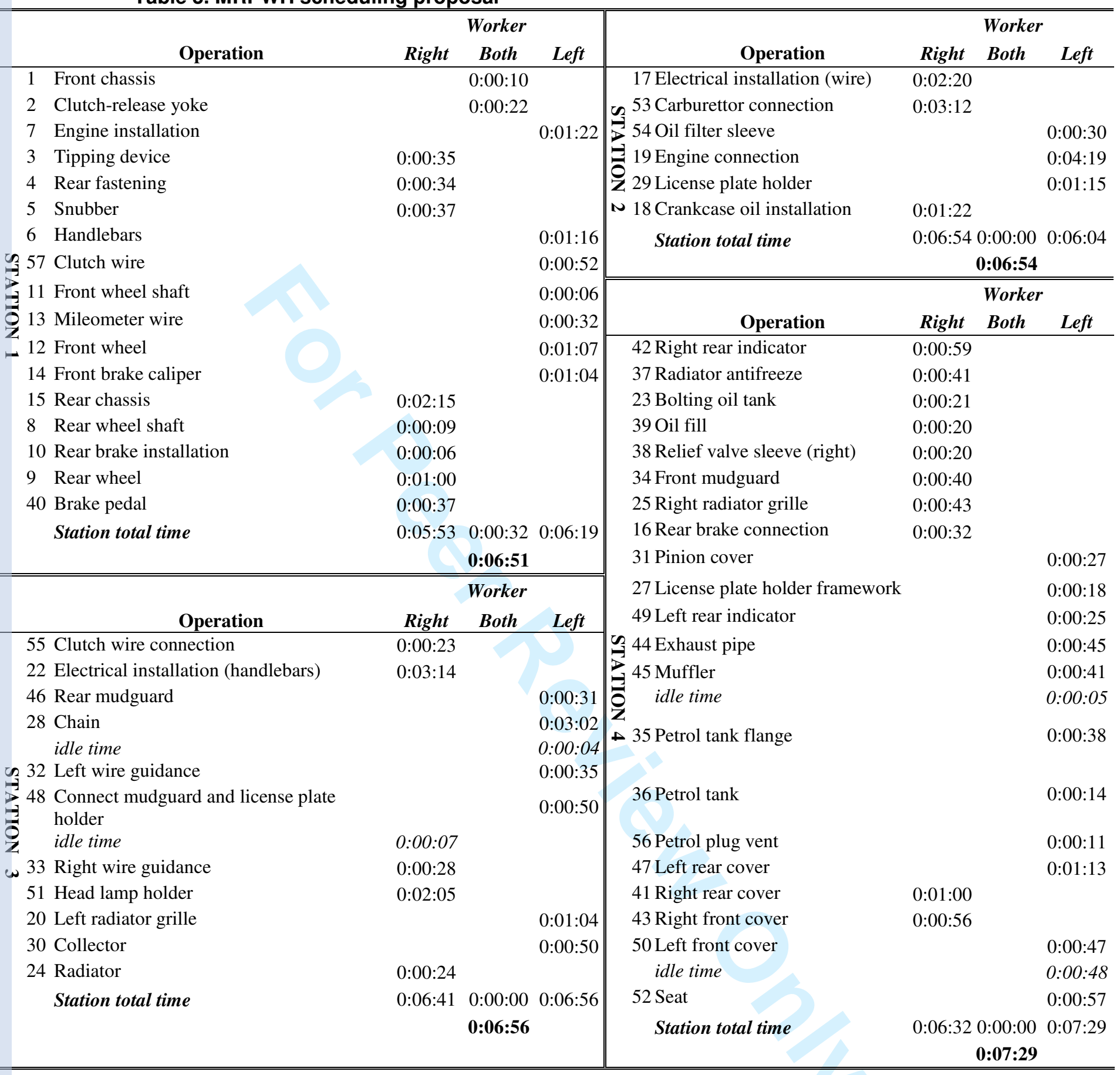


Table 4. MSNSH algorithm pseudocode

$\mathrm{W}=1$

Do

Do

Do

Do

$$
\text { If } \mathrm{w}=1 \text { Random selection in } V^{E}\left(x_{i}\right) \rightarrow
$$

$V_{i}\left(x_{i}\right)$

$$
\text { Else Random selection in } V\left(x_{i}\right) \rightarrow V_{i}\left(x_{i}\right)
$$

While neighbour feasibility test fails

Calculate $f\left(V_{i}\left(x_{i}\right)\right)$

If $f\left(V_{i}\left(x_{i}\right)\right)<f($ Best_V(xi))

Best_V $(x i) \leftarrow V_{i}\left(x_{i}\right)$

While $\left[f(\right.$ Best_V $\left.(\mathrm{xi}))>f\left(V_{i}\left(x_{i}\right)\right)\right] \quad$ OR Iterations <

$\mathrm{N}_{\text {loop }}$

If $f($ Best_V(xi) $)<f\left(V_{i}\left(x_{i}\right)\right) \quad x i \leftarrow$ Best_V(xi)

If $\mathrm{w}=1$ Calculate New_bottleneck_station $\rightarrow \mathrm{E}$

While Iterations $<\mathrm{N}_{\mathrm{w}}$ $\mathrm{w}=0$

While Iterations $<\mathrm{N}_{\mathrm{H}}$ 
Table 5. MSNSH scheduling proposal

\begin{tabular}{|c|c|c|c|c|c|c|}
\hline \multirow{3}{*}{$\begin{array}{cc} & \\
& \text { Operation } \\
1 & \text { Front chassis }\end{array}$} & \multicolumn{3}{|c|}{ Worker } & \multirow[b]{2}{*}{ Operation } & \multicolumn{2}{|l|}{ Worker } \\
\hline & Right & Both & Left & & Right Both & Left \\
\hline & & 0:00:10 & & 17 Electrical installation (wire) & $0: 02: 20$ & \\
\hline 2 Clutch-release yoke & & 0:00:22 & & 53 Carburettor connection & 0:03:12 & \\
\hline 7 Engine installation & & & $0: 01: 22$ & 54 Oil filter sleeve & & $0: 00: 30$ \\
\hline 3 Tipping device & 0:00:35 & & & If Engine connection & & 0:04:19 \\
\hline 4 Rear fastening & 0:00:34 & & & Z 29 License plate holder & & $0: 01: 15$ \\
\hline 5 Snubber & 0:00:37 & & & N 18 Crankcase oil installation & 0:01:22 & \\
\hline 6 Handlebars & & & $0: 01: 16$ & Station total time & 0:06:54 0:00:00 & 0:06:04 \\
\hline 57 Clutch wire & & & 0:00:52 & & \multicolumn{2}{|c|}{ 0:06:54 } \\
\hline 11 Front wheel shaft & & & 0:00:06 & & \multicolumn{2}{|l|}{ Worker } \\
\hline ō 13 Mileometer wire & & & 0:00:32 & Operation & Right Both & Left \\
\hline 12 Front wheel & & & 0:01:07 & 42 Right rear indicator & 0:00:59 & \\
\hline 14 Front brake caliper & & & 0:01:04 & 37 Radiator antifreeze & 0:00:41 & \\
\hline 15 Rear chassis & 0:02:15 & & & 23 Bolting oil tank & 0:00:21 & \\
\hline 8 Rear wheel shaft & 0:00:09 & & & 39 Oil fill & 0:00:20 & \\
\hline 10 Rear brake installation & 0:00:06 & & & 38 Relief valve sleeve (right) & 0:00:20 & \\
\hline 9 Rear wheel & 0:01:00 & & & 35 Petrol tank flange & 0:00:38 & \\
\hline 40 Brake pedal & $0: 00: 37$ & & & 25 Right radiator grille & $0: 00: 43$ & \\
\hline \multirow[t]{2}{*}{ Station total time } & 0:05:53 & 0:00:32 & 0:06:19 & 43 Right front cover & 0:00:56 & \\
\hline & \multicolumn{3}{|c|}{ 0:06:51 } & 31 Pinion cover & & $0: 00: 27$ \\
\hline \multirow[b]{2}{*}{ Operation } & \multicolumn{3}{|c|}{ Worker } & \multicolumn{2}{|l|}{27 License plate holder framework } & $0: 00: 18$ \\
\hline & Right & \multicolumn{2}{|l|}{ Both } & 49 Left rear indicator & & $0: 00: 25$ \\
\hline 55 Clutch wire connection & $0: 00: 23$ & 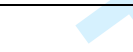 & & \multicolumn{2}{|l|}{44 Exhaust pipe } & $0: 00: 45$ \\
\hline 22 Electrical installation (handlebars) & 0:03:14 & & & \multirow{2}{*}{\multicolumn{2}{|c|}{$\begin{array}{l}35 \text { Muffler } \\
34 \text { Front mudguard }\end{array}$}} & 0:00:41 \\
\hline 46 Rear mudguard & & & 0:00:31 & & & $0: 00: 40$ \\
\hline 28 Chain & \multirow{4}{*}{ 0:00:35 } & & 0:03:02 & \multicolumn{2}{|l|}{$+\quad$ idle time } & 0:00:03 \\
\hline \multirow{3}{*}{$\begin{array}{l}\text { idle time } \\
32 \text { Left wire guidance } \\
24 \text { Radiator } \\
48 \text { Connect mudguard to license plate } \\
\text { w holder } \\
\omega_{33} \text { Right wire guidance }\end{array}$} & & & $0: 00: 04$ & 36 Petrol tank & & $0: 00: 14$ \\
\hline & & & 0:00:24 & \multirow{2}{*}{$\begin{array}{l}56 \text { Petrol plug vent } \\
47 \text { Left rear cover }\end{array}$} & & $0: 00: 11$ \\
\hline & & & 0:00:50 & & & 0:01:13 \\
\hline w 33 Right wire guidance & 0:00:28 & & & 41 Right rear cover & 0:01:00 & \\
\hline 51 Head lamp holder & 0:02:05 & & & 16 Rear brake connection & 0:00:32 & \\
\hline \multirow{2}{*}{$\begin{array}{l}20 \text { Left radiator grille } \\
30 \text { Collector }\end{array}$} & & & 0:01:04 & \multirow{2}{*}{$\begin{array}{l}50 \text { Left front cover } \\
\text { idle time }\end{array}$} & & $0: 00: 47$ \\
\hline & & & 0:00:50 & & & $0: 00: 14$ \\
\hline \multirow[t]{2}{*}{ Station total time } & 0:06:45 & 0:00:00 & 0:06:45 & 52 Seat & & $0: 00: 57$ \\
\hline & & 0:06:45 & & Station total time & $\begin{array}{r}0: 06: 30 \text { 0:00:00 } \\
\mathbf{0 : 0 6 : 5 5} \\
\end{array}$ & $0: 06: 55$ \\
\hline
\end{tabular}


Table 6. Daily productivity results

\begin{tabular}{|l|c|c|c|}
\hline & Daily average productivity & Standard deviation & Interval \\
\hline MH initial scenario & 35.20 & 0.51 & $(34,36)$ \\
\hline MRPWH heuristic & 56.25 & 0.70 & $(55,57)$ \\
\hline MSNSH heuristic & 57.05 & 0.44 & $(56,58)$ \\
\hline
\end{tabular}




\section{LIST OF FIGURE CAPTIONS}

Figure 1. FURIA XP6 motorcycle model

Figure 2. Layout of the manufacturing plant

Figure 3. Workers on the assembly line carrying out operations

Figure 4. Solutions encoding

Figure 5. Station performance modules

Figure 6. Operation modules in Stations 1, 2 and 3. MSNSH heuristic solution

Figure 7. Operation modules in Station 4. MSNSH heuristic solution

Figure 8. Animation module of the simulation model

Figure 9. Operation time in the stations.

Figure 10. Waiting times in the assembly line

Figure 11. Comparison of workers' activity for the proposals

Figure 12. Analysis of the productivity with respect to the replications 


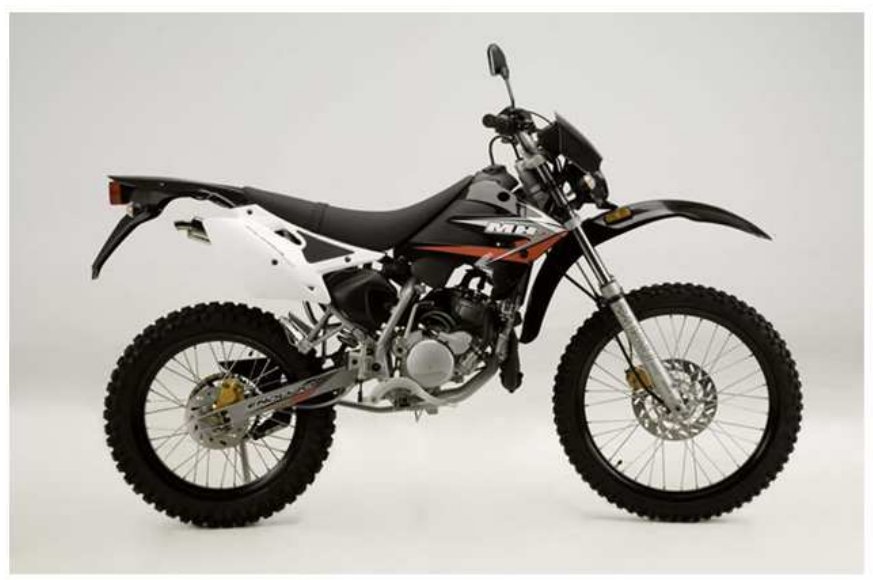

Figure 1. FURIA XP6 motorcycle model $254 \times 190 \mathrm{~mm}(96 \times 96 \mathrm{DPI})$ 


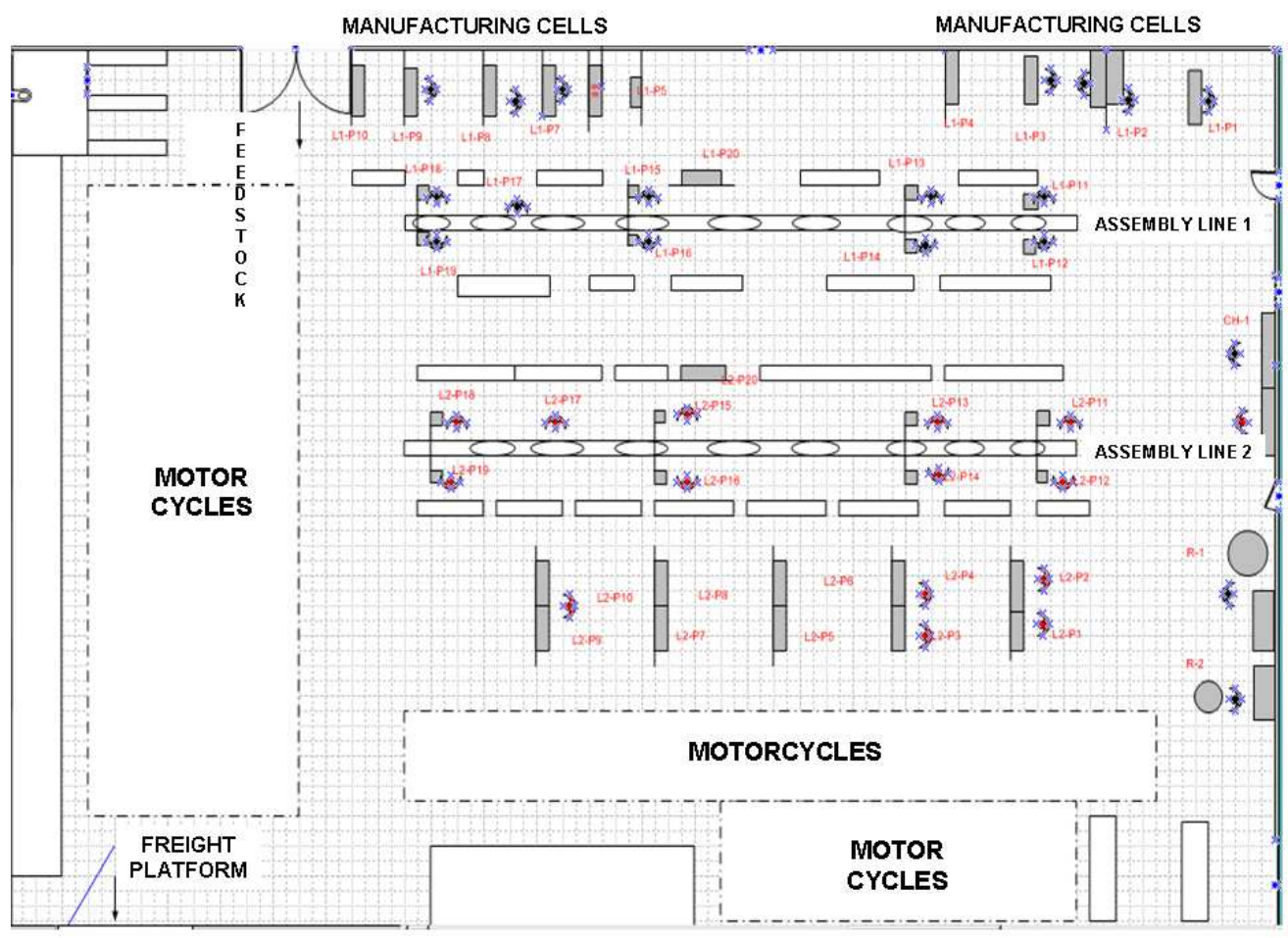

Figure 2. Layout of the manufacturing plant $254 \times 190 \mathrm{~mm}(96 \times 96 \mathrm{DPI})$ 


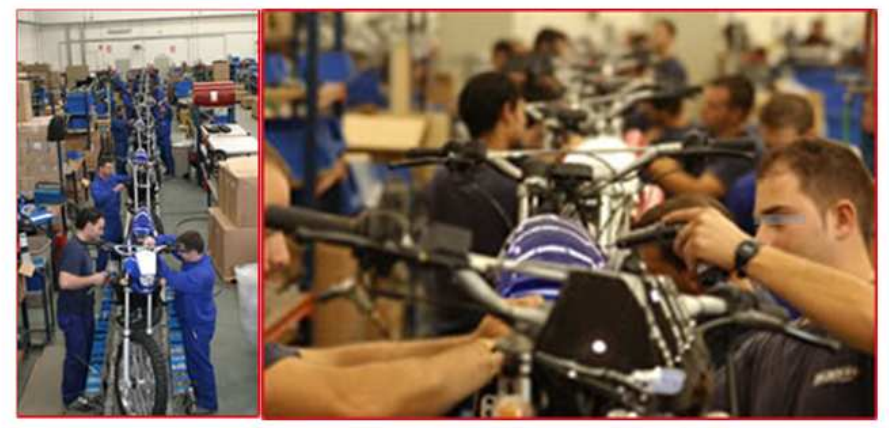

Figure 3 . Workers on the assembly line carrying out operations 254x190mm (96 x 96 DPI) 
Figure 4. Solutions encoding $254 \times 190 \mathrm{~mm}(96 \times 96 \mathrm{DPI})$ 

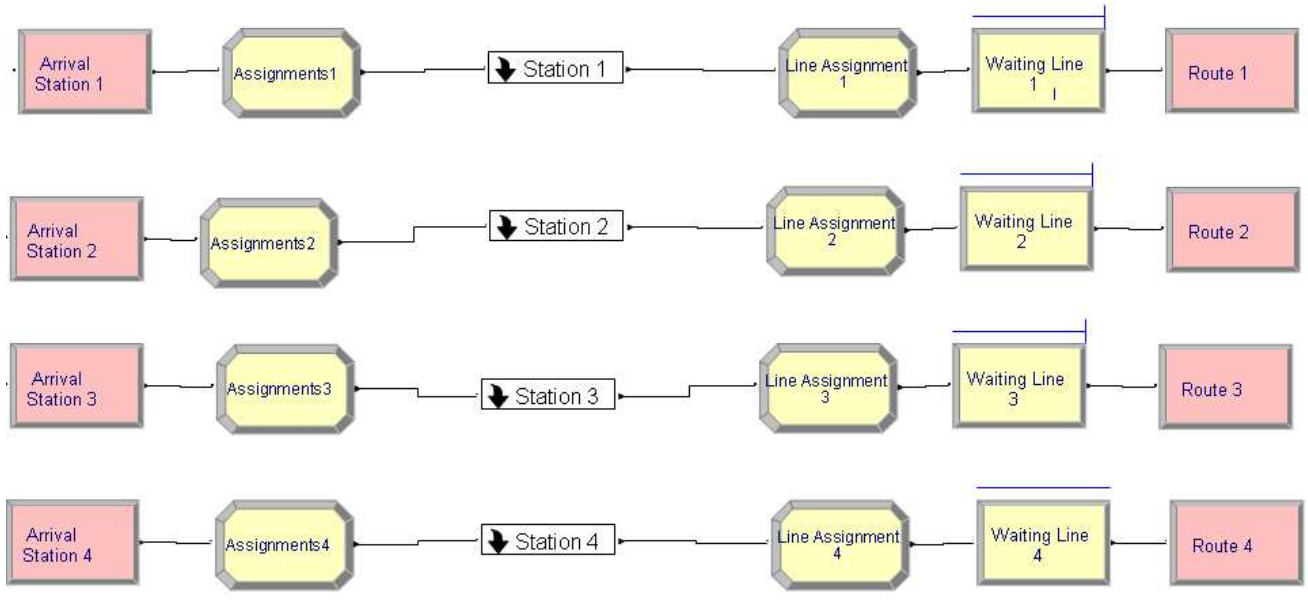

Figure 5. Station performance modules 254x190mm (96 x 96 DPI) 

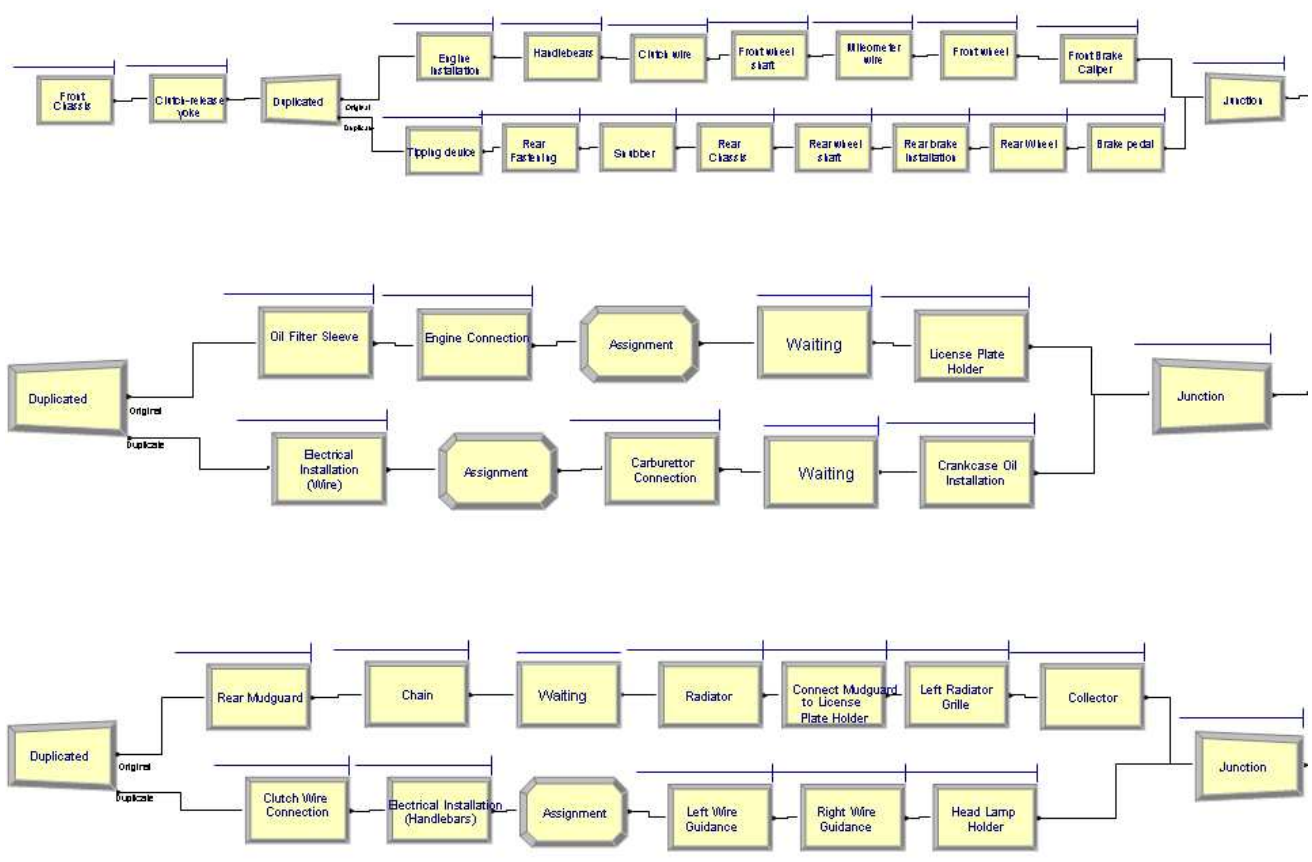

Figure 6. Operation modules in Stations 1, 2 and 3. MSNSH heuristic solution $254 \times 190 \mathrm{~mm}(96 \times 96 \mathrm{DPI})$ 


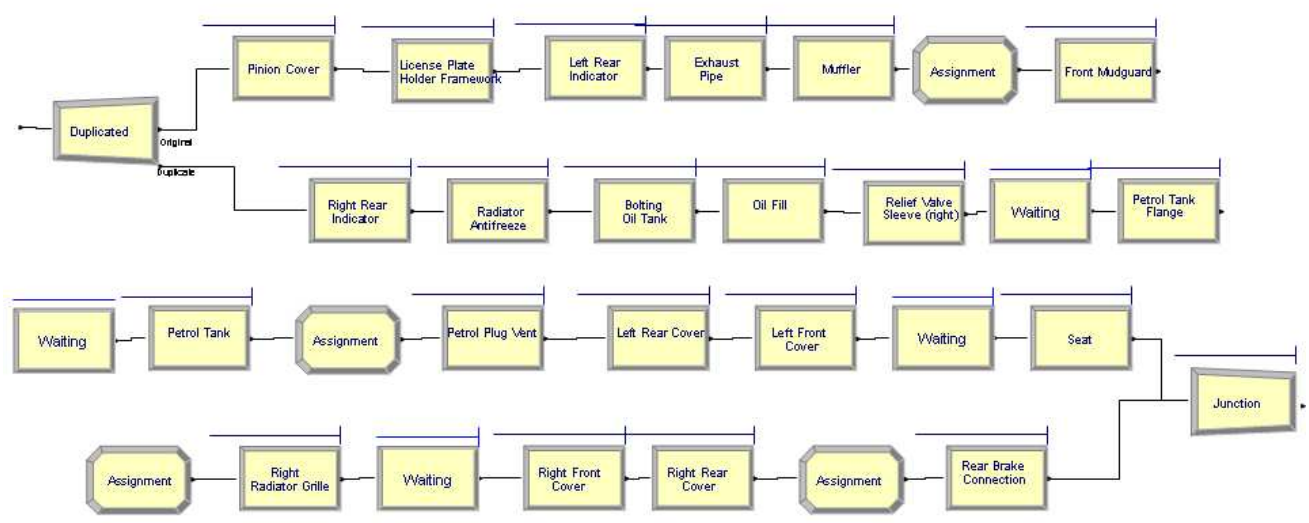

Figure 7. Operation modules in Station 4. MSNSH heuristic solution $254 \times 190 \mathrm{~mm}(96 \times 96$ DPI) 


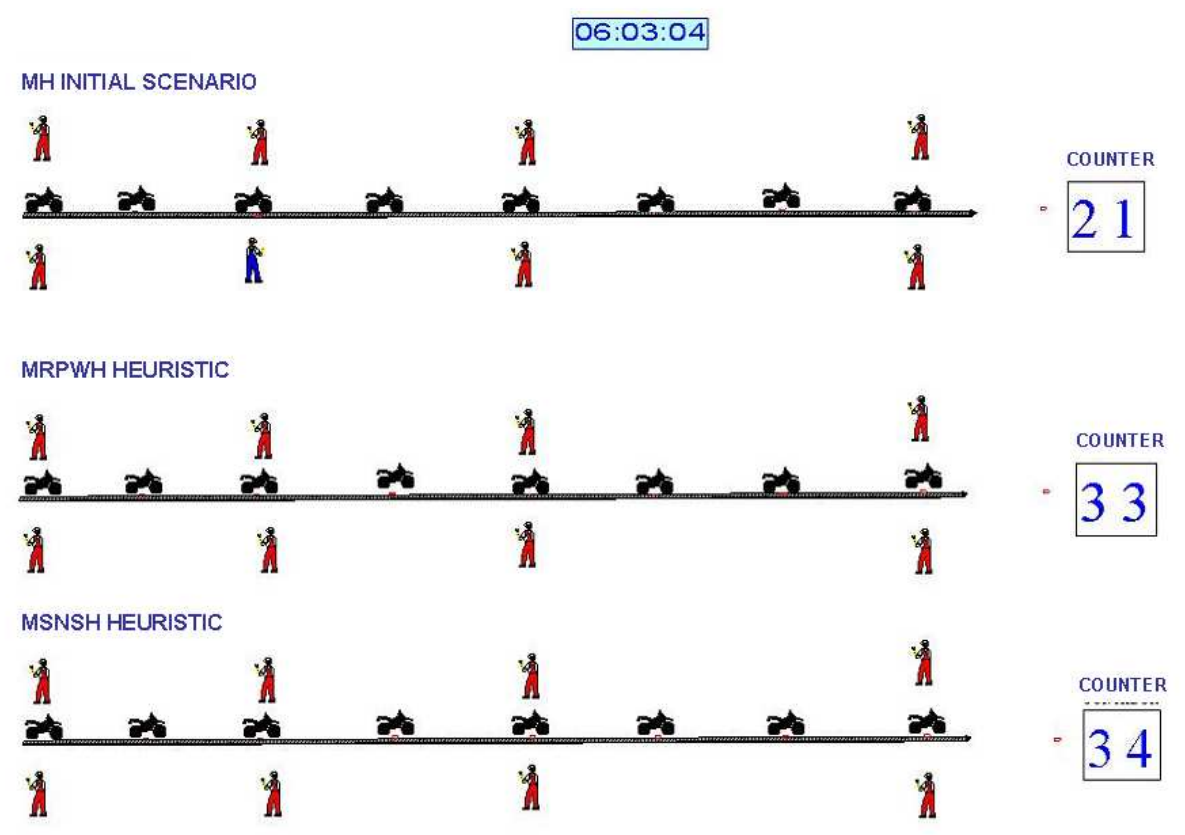

Figure 8. Animation module of the simulation model $254 \times 190 \mathrm{~mm}$ ( $96 \times 96$ DPI) 


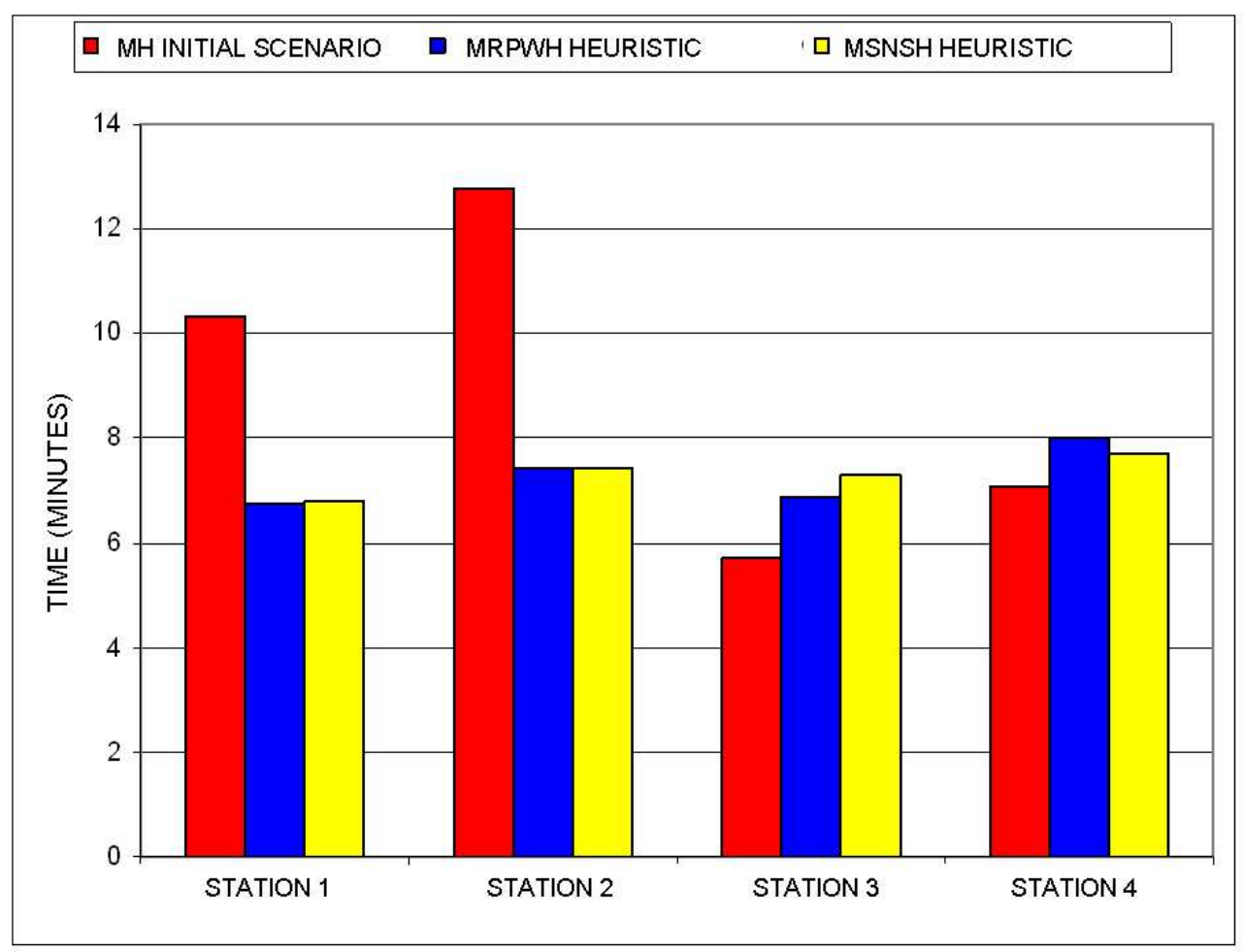

Figure 9. Operation time in the stations. 254x190mm (96 x 96 DPI) 

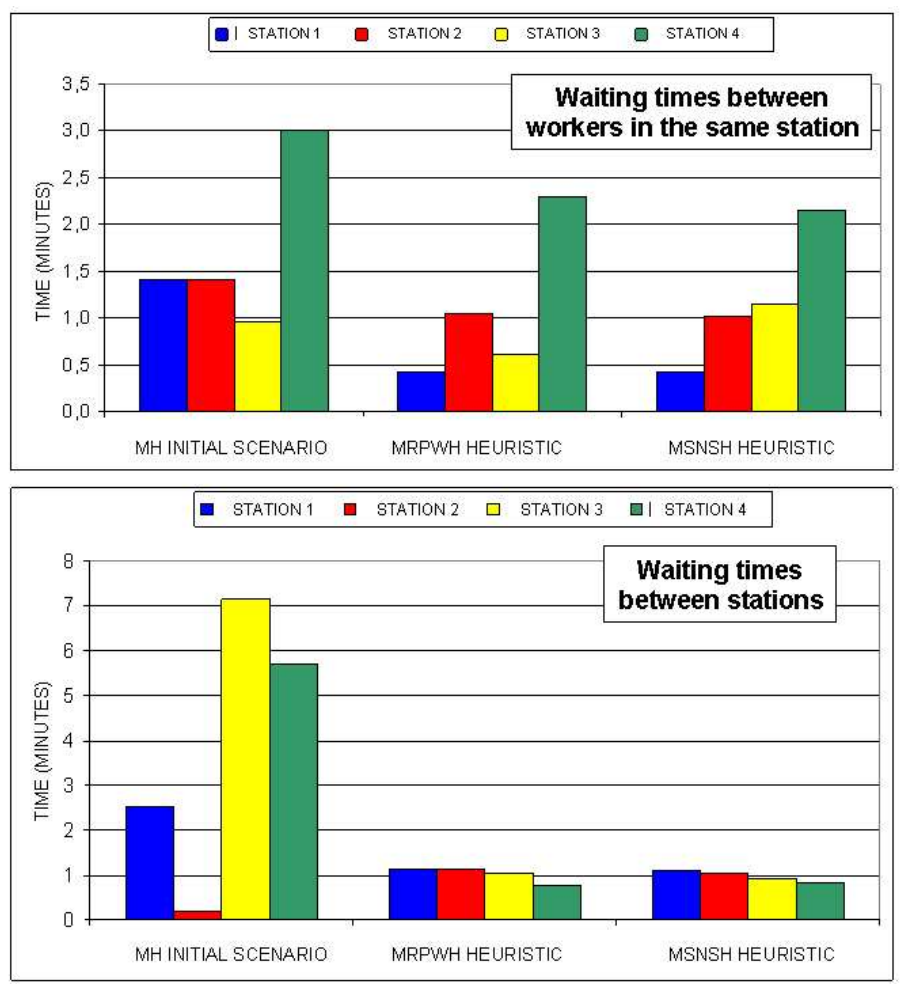

Figure 10. Waiting times in the assembly line $254 \times 190 \mathrm{~mm}(96 \times 96 \mathrm{DPI})$ 

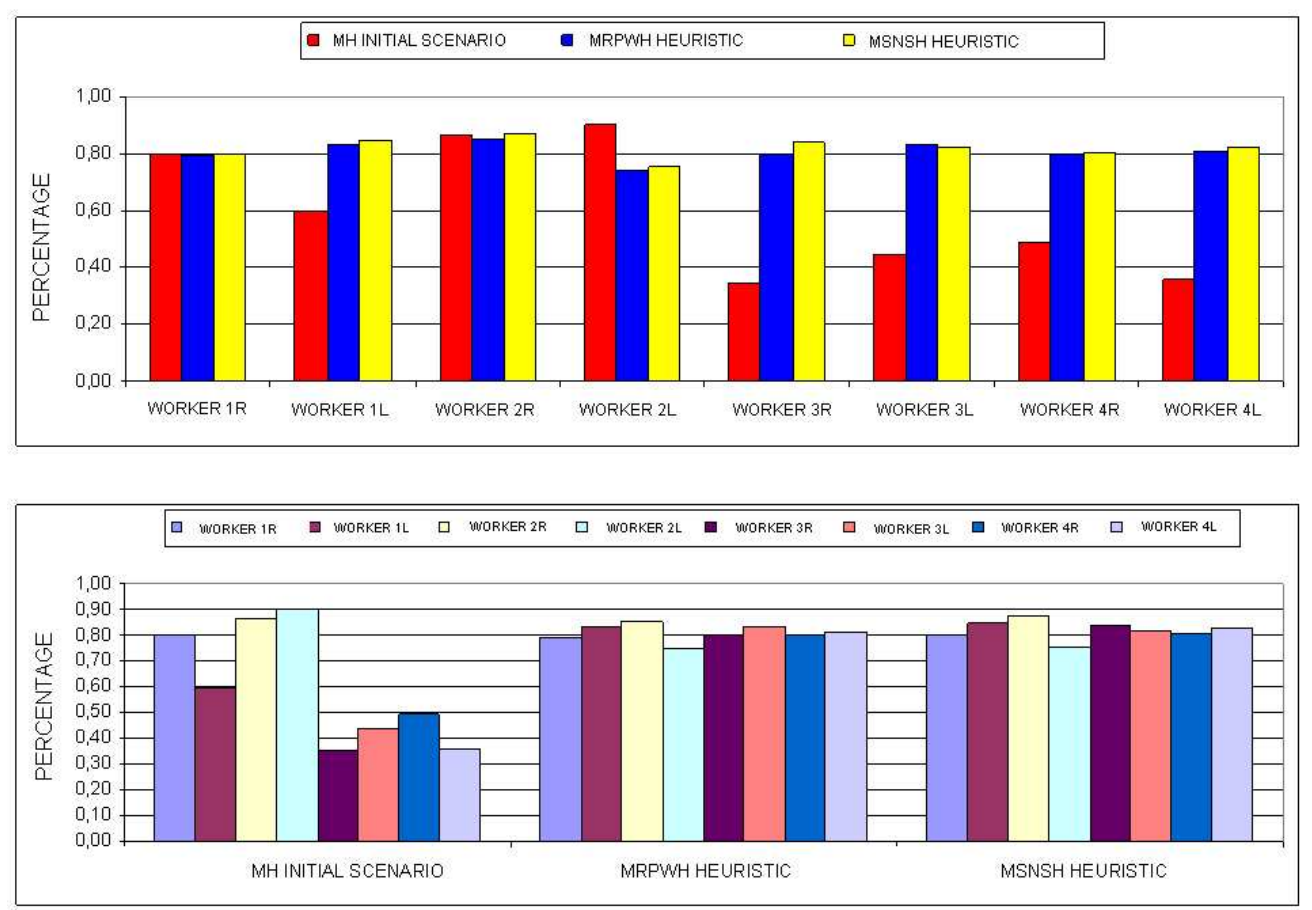

Figure 11. Comparison of workers' activity for the proposals $254 \times 190 \mathrm{~mm}(96 \times 96 \mathrm{DPI})$ 
Figure 12 . Analysis of the productivity with respect to the replications $254 \times 190 \mathrm{~mm}(96 \times 96 \mathrm{DPI})$ 